\title{
Determinan customer satisfaction dan customer loyalty pada klinik kandungan
}

\author{
Nevi Chania Dwi Ariyanti ${ }^{1}$, Soenarmi ${ }^{2}$ \\ ${ }^{1 \& 2}$ Fakultas Ekonomi dan Bisnis Universitas Wijaya Putra Surabaya \\ nevichania@gmail.com
}

\begin{abstract}
This study aims to examine and analyze the effect of Physical Evidence, Trust, and E-Service Quality on Customer Loyalty through Customer Satisfaction. In this study using a quantitative approach, because research data in the form of number and analysis using statistics. Data analysis techniques to answer hypothese using path analysis. The results showed that: (1) Physical Evidence had a significant effect on Customer Satisfaction, (2) Trust had a significant effect on Customer Satisfaction, (3) E-Service Quality had a significant effect on Customer Satisfaction, (4) Physical Evidence had a significant effect on Customer Loyalty, (5) Trust has no significant effect on Customer Loyalty, (6) E-Service Quality has no significant effect on Customer Loyalty, (7) Customer Satisfaction had a significant effect on Customer Loyalty.
\end{abstract}

Keywords: Physical evidence, trust, e-service quality, customer satisfaction, customer loyalty.

\begin{abstract}
Abstrak: Penelitian ini bertujuan untuk menguji dan menganalisis pengaruh Physical Evidence, Trust, dan E-Service Quality terhadap Customer Loyalty melalui Customer Satisfaction. Dalam penelitian ini menggunakan pendekatan kuantitatif, karena data penelitian berupa angka-angka dan analisis menggunakan statistik. Teknik analisis data untuk menjawab hipotesis menggunakan path analysis. Hasil penelitian menunjukkan bahwa: (1) Physical Evidence berpengaruh signifikan terhadap Customer Satisfaction, (2) Trust berpengaruh signifikan terhadap Customer Satisfaction, (3) E-Service Quality berpengaruh signifikan terhadap Customer Satisfaction, (4) Physical Evidence berpengaruh signifikan terhadap Customer Loyalty, (5) Trust tidak berpengaruh signifikan terhadap Customer Loyalty, (6) E-Service Quality tidak berpengaruh signifikan terhadap Customer Loyalty, (7) Customer Satisfaction berpengaruh signifikan terhadap Customer Loyalty.
\end{abstract}

Kata Kunci: Physical Evidence, Trust, E-Service Quality, Customer Satisfaction, Customer Loyalty. 


\section{PENDAHULUAN}

Perkembangan teknologi dalam era modern saat ini sangat maju, banyak orang berlomba-lomba untuk menciptakan peralatan penunjang kehidupan agar hidup lebih efektif dan efisien. Seperti halnya dalam dunia medis atau kesehatan, banyak peralatanperalatan baru yang semakin canggih dan semakin hebat dalam mendeteksi keadaan pasien, tak luput peralatan yang digunakan dalam pemeriksaan kandungan.

Klinik kandungan merupakan klinik spesialis yang melayani pemeriksaan kehamilan, penyakit kandungan dan persalinan. Banyak pasien yang ingin mengetahui bagaimana keadaan dari calon bayinya, terlebih pasangan muda atau pasangan yang telah lama menikah dan baru dikaruniai seorang anak. Beberapa alasan pasien untuk periksa di Klinik Kandungan dr.Iman Sp.OG ini ialah seperti, kepercayaan ( Trust ) pasien bahwa klinik ini ditangani oleh dokter spesialis kandungan dengan pengalaman yang sudah kompeten dalam bidangnya. Klinik Kandungan dr.Iman, Sp.OG sudah menggunakan fasilitas USG 4D. Pemeriksaan menggunakan alat USG 4D ini belum tersedia di beberapa rumahsakit maupun praktek bidan mandiri di wilayah Surabaya Barat, khususnya di Kelurahan Kandangan, Benowo, Pakal, Sambikerep, dan daerah perbatasan Surabaya - Gresik. Kualitas layanan pemeriksaan di Klinik Kandungan dr.Iman, Sp.OG ditingkatkan dengan memanfaatkan perkembangan teknologi, yakni dengan memberikan layanan elektronik (E-Service Quality). Salah satu kualitas layanan elektronik tersebut adalah klinik ini sudah menggunakan sistem online untuk antriannya. Sistem antrian secara online dapat memudahkan para pasien untuk mendaftar, khususnya bagi pasien yang bertempat tinggal jauh dari lokasi klinik, sehingga dapat lebih menghemat biaya transportasi.

Dengan antusiasnya para pasien, dari sini banyak penyimpangan-penyimpangan yang terjadi saat proses pelaksanaan pemeriksaan. Pasien-pasien tidak mematuhi prosedur yang ada. Banyak pasien yang menghalalkan segala cara agar bisa diperiksa di klinik tersebut. Selain itu ada beberapa penyimpangan yang terjadi seperti, pasien yang dengan keadaan baik-baik saja menggunakan alasan bahwa dirinya sedang mengalami kesakitan yang sangat parah agar bisa diperiksa di klinik ini, kemudian pasien menyatakan ada hubungan kerabat dengan dr.Iman, Sp.OG, selain itu juga banyak pasien yang menggunakan alasan tempat tinggal yang jauh agar bisa cepat untuk bisa diperiksa, serta masih banyak alasan-alasan lain lagi.

Hasil kajian empiris tentang pengaruh physical evidence, trust, dan e-service quality terhadap customer loyalty melalui customer satisfaction, seperti penelitian yang dilakukan oleh Ganang Setianto dan Sri Wartini (2017) menyatakan bahwa terdapat pengaruh Bukti Fisik secara positif dan signifikan terhadap Kepuasan Konsumen dan Loyalitas Konsumen. Namun dalam penelitian yang dilakukan Arief Surachman dan Elvira Azis (2017) menyatakan bahwa Bukti Fisik tidak berpengaruh signifikan terhadap Loyalitas Pelanggan. Kemudian hasil penelitian yang dilakukan oleh Nurlaely 
(2016) menjelaskan bahwa Kepercayaan berpengaruh positif dan signifikan terhadap Kepuasan Pelanggan dan Loyalitas Pelanggan. Namun dalam penelitian Jeremia Kolonio dan Djurwati Soepeno (2019) ditemukan bahwa Kepercayaan tidak berpengaruh signifikan terhadap Loyalitas Konsumen. Selain itu, penelitian Felicia Laurent (2016) juga menyatakan bahwa E-Service Quality berpengaruh signifikan terhadap variabel Customer Satisfaction dan Customer Loyalty pada transaksi penggunaan layanan Gojek. Namun, ada hasil yang berbeda dari gap penelitian Imam Suyadi dkk (2017), E-Service Quality secara langsung berpengaruh tidak signifikan terhadap E-Customer Loyalty dan E-Customer Satisfaction pada nasabah Bank BRI KCP Lawang. Dengan demikian, tujuan dari penelitian ini adalah untuk menguji dan menganalisis pengaruh Physical Evidence, Trust, dan E-Service Quality terhadap Customer Loyalty melalui Customer Satisfaction pada Klinik Kandungan dr.Iman,Sp.OG.

\section{METODE PENELITIAN}

Jenis penelitian yang akan digunakan untuk menunjukkan adanya hubungan antara Physical Evidence (X1), Trust (X2), dan E-Service Quality (X3) terhadap Customer Loyalty (Y2) melalui Customer Satisfaction (Y1) adalah penelitian kausal. Pendekatan yang digunakan adalah pendekatan kuantitatif, karena data penelitian berupa angka-angka dan analisis menggunakan statistik. Lokasi penelitian dilakukan di Klinik Kandungan dr.Iman, Sp.OG yang berada di Jl. Raya Kendung No.61, Sememi, Benowo, Surabaya. Dipilihnya tempat ini sebagai obyek penelitian adalah lokasi penelitian dekat dengan tempat tinggal peneliti, selain itu klinik ini mampu menarik banyak minat pasien untuk periksa ke tempat tersebut.

Populasi penelitian ini yaitu pasien Klinik Kandungan dr.Iman,Sp.OG. Adapun yang menjadi sampel adalah pasien sebanyak 100 orang. Teknik pengambilan sampel dalam penelitian ini adalah non probability sampling dengan metode incidental sampling yaitu penentuan sampel yang diambil secara kebetulan bertemu dengan peneliti pada waktu tertentu dengan karakteristik minimal periksa $1 \mathrm{x}$ dalam kurun waktu 1 bulan terakhir (Periode Mei-Juni 2019). Sumber data diperoleh dari data primer dan data sekunder. Metode pengumpulan data dari penelitian ini melalui studi kepustakaan, kuisioner dan dokumentasi. Untuk menguji keabsahan data menggunakan uji validitas dan uji reliabilitas. Sedangkan teknik analisis data menggunakan uji hipotesis berupa analisis path yang meliputi uji koefisien determinasi, uji t, dan uji F. Alat uji yang digunakan adalah SPSS versi 25. 


\section{HASIL DAN PEMBAHASAN}

\section{Hasil Uji Keabsahan Data}

\section{Uji Validitas}

Tabel 1. Hasil Uji Validitas

\begin{tabular}{|c|c|c|c|c|}
\hline Variabel & Indikator & Koefisien Korelasi & Signifikansi & Keterangan \\
\hline \multirow{8}{*}{ Physical Evidence $\left(\mathrm{X}_{1}\right)$} & $\mathrm{X} 1.1$ & 0,836 & 0,000 & Valid \\
\hline & $\mathrm{X} 1.2$ & 0,806 & 0,000 & Valid \\
\hline & $\mathrm{X} 1.3$ & 0,721 & 0,000 & Valid \\
\hline & $\mathrm{X} 1.4$ & 0,832 & 0,000 & Valid \\
\hline & $\mathrm{X} 1.5$ & 0,843 & 0,000 & Valid \\
\hline & $\mathrm{X} 1.6$ & 0,830 & 0,000 & Valid \\
\hline & $\mathrm{X} 1.7$ & 0,749 & 0,000 & Valid \\
\hline & $\mathrm{X} 1.8$ & 0,806 & 0,000 & Valid \\
\hline \multirow{3}{*}{ Trust $\left(\mathrm{X}_{2}\right)$} & $\mathrm{X} 2.1$ & 0,815 & 0,000 & Valid \\
\hline & $\mathrm{X} 2.2$ & 0,835 & 0,000 & Valid \\
\hline & $\mathrm{X} 2.3$ & 0,885 & 0,000 & Valid \\
\hline \multirow{5}{*}{ E-Service Quality $\left(\mathrm{X}_{3}\right)$} & $\mathrm{X} 3.1$ & 0,700 & 0,000 & Valid \\
\hline & X3.2 & 0,786 & 0,000 & Valid \\
\hline & X3.3 & 0,760 & 0,000 & Valid \\
\hline & X3.4 & 0,759 & 0,000 & Valid \\
\hline & $\mathrm{X} 3.5$ & 0,678 & 0,000 & Valid \\
\hline \multirow{3}{*}{ Customer Satisfaction $\left(\mathrm{Y}_{1}\right)$} & Y1.1 & 0,895 & 0,000 & Valid \\
\hline & $\mathrm{Y} 1.2$ & 0,851 & 0,000 & Valid \\
\hline & Y1.3 & 0,824 & 0,000 & Valid \\
\hline \multirow{5}{*}{ Customer Loyalty $\left(\mathrm{Y}_{2}\right)$} & Y2.1 & 0,708 & 0,000 & Valid \\
\hline & Y2.2 & 0,829 & 0,000 & Valid \\
\hline & Y2.3 & 0,798 & 0,000 & Valid \\
\hline & $\mathrm{Y} 2.4$ & 0,830 & 0,000 & Valid \\
\hline & $\mathrm{Y} 2.5$ & 0,811 & 0,000 & Valid \\
\hline
\end{tabular}

Dari tabel 3.1 dapat diketahui bahwa untuk item pertanyaan, semua variabel koefisien korelasinya $>0,3$ dan tingkat signifikansinya $<0,05$, berarti secara keseluruhan item pertanyaan mengenai Physical Evidence (X1), Trust (X2), E-Service Quality (X3), Customer Satisfaction (Y1) dan Customer Loyalty (Y2) adalah Valid. 
IMKA Implementasi Manajemen \& Kewirausahaan - April, Vol. 1, No. 1, 30-42, 2021

\section{Uji Reliabilitas}

Tabel 2. Hasil Uji Reliabilitas

\begin{tabular}{|l|c|c|c|c|}
\hline \multicolumn{1}{|c|}{ Variabel } & Cronbach Alpha & Reliabilitas Minimum & N of Item & Keterangan \\
\hline Physical Evidence $\left(\mathrm{X}_{1}\right)$ & 0,789 & 0,3 & 100 & Reliabel \\
\hline Trust $\left(\mathrm{X}_{2}\right)$ & 0,844 & 0,3 & 100 & Reliabel \\
\hline E-Service Quality $\left(\mathrm{X}_{3}\right)$ & 0,788 & 0,3 & 100 & Reliabel \\
\hline Customer Satisfaction $\left(\mathrm{Y}_{1}\right)$ & 0,848 & 0,3 & 100 & Reliabel \\
\hline Customer Loyalty $\left(\mathrm{Y}_{2}\right)$ & 0,804 & 0,3 & 100 & Reliabel \\
\hline
\end{tabular}

Dari hasil pengujian yang dilakukan terhadap reliabilitas kuisioner diperoleh hasil bahwa nilai Cronbach Alpha dalam semua item pernyataan kuisioner untuk masingmasing variabel lebih besar dari 0,3 ( > 0,3). Dapat disimpulkan bahwa semua item pernyataan untuk masing-masing variabel dinyatakan telah reliabel.

\section{Hasil Teknik Analisis Data}

\section{A. Koefisien Determinasi}

Tabel 3. Hasil Uji Koefisien Determinasi

\begin{tabular}{|c|c|c|c|c|}
\hline \multicolumn{5}{|c|}{ Model Summary $^{\mathbf{b}}$} \\
\hline Model & $\mathrm{R}$ & R Square & Adjusted R Square & $\begin{array}{l}\text { Std. Error of the } \\
\text { Estimate }\end{array}$ \\
\hline 1 & $.700^{\mathrm{a}}$ & .490 & .474 & .986 \\
\hline
\end{tabular}

a. Predictors: (Constant), E-Service Quality, Physical Evidence, Trust

b. Dependent Variable: Customer Satisfaction

Sumber : Hasil Olah Data SPSS

Besarnya angka R Square (r2) adalah 0,490. Angka tersebut mempunyai maksud bahwa pengaruh Physical Evidence (X1), Trust (X2), dan E-Service Quality (X3) terhadap Customer Satisfaction (Y1) adalah 49\%, sedangkan sisanya sebesar $51 \%$ $(100 \%-49 \%)$ dipengaruhi oleh faktor lain diluar variabel ini.

Tabel 4. Hasil Uji Koefisien Determinasi

\begin{tabular}{|c|c|c|c|c|}
\hline \multicolumn{5}{|c|}{ Model Summary $^{\mathbf{b}}$} \\
\hline Model & $\mathrm{R}$ & R Square & Adjusted R Square & $\begin{array}{c}\text { Std. Error of the } \\
\text { Estimate }\end{array}$ \\
\hline 1 & $.815^{\mathrm{a}}$ & .663 & .649 & 1.248 \\
\hline
\end{tabular}

a. Predictors: (Constant), Customer Satisfaction, E-Service Quality, Physical Evidence, Trust

b. Dependent Variable: Customer Loyalty

Sumber : Hasil Olah Data SPSS 
Besarnya angka R Square (r2) adalah 0,663. Angka tersebut mempunyai maksud bahwa pengaruh Physical Evidence (X1), Trust (X2), E-Service Quality (X3), dan Customer Satisfaction (Y1) terhadap Customer Loyalty (Y2) adalah 66,3\%, sedangkan sisanya sebesar 33,7\% (100\% - 66,3\%) dipengaruhi oleh faktor lain diluar variabel ini

\section{B. Uji t}

Tabel 5. Hasil Uji t

\begin{tabular}{|c|c|c|c|c|c|c|}
\hline \multicolumn{7}{|c|}{ Coefficients $^{\mathbf{a}}$} \\
\hline & & \multicolumn{2}{|c|}{$\begin{array}{c}\text { Unstandardized } \\
\text { Coefficients } \\
\end{array}$} & \multirow{3}{*}{$\begin{array}{c}\text { Standardized } \\
\text { Coefficients } \\
\text { Beta } \\
\end{array}$} & \multirow{3}{*}{$\frac{\mathrm{t}}{.897}$} & \multirow{3}{*}{$\begin{array}{r}\text { Sig. } \\
.372 \\
\end{array}$} \\
\hline \multicolumn{2}{|c|}{ Model } & $\mathrm{B}$ & Std. Error & & & \\
\hline \multirow[t]{4}{*}{1} & (Constant) & .939 & 1.047 & & & \\
\hline & Physical Evidence & .103 & .042 & .230 & 2.484 & .015 \\
\hline & Trust & .443 & .113 & .409 & 3.928 & .000 \\
\hline & E-Service Quality & .117 & .057 & .183 & 2.053 & .043 \\
\hline
\end{tabular}

a. Dependent Variable: Customer Satisfaction

Sumber : Hasil Olah Data SPSS

Tabel 6. Hasil Uji t

Coefficients $^{\mathbf{a}}$

\begin{tabular}{|c|c|c|c|c|c|c|}
\hline & & $\begin{array}{r}\text { Unst } \\
\mathrm{Co} \\
\end{array}$ & $\begin{array}{l}\text { dardized } \\
\text { icients }\end{array}$ & $\begin{array}{c}\text { Standardized } \\
\text { Coefficients }\end{array}$ & & \\
\hline & & $\mathrm{B}$ & Std. Error & Beta & $\mathrm{t}$ & Sig. \\
\hline 1 & (Constant) & 1.623 & 1.331 & & 1.220 & .226 \\
\hline & Physical Evidence & .159 & .054 & .229 & 2.933 & .004 \\
\hline & Trust & .110 & .154 & .065 & .712 & .478 \\
\hline & E-Service Quality & .025 & .073 & .026 & .344 & .731 \\
\hline & Customer Satisfaction & .931 & .129 & .601 & 7.204 & .000 \\
\hline
\end{tabular}

a. Dependent Variable: Customer Loyalty

Sumber : Hasil Olah Data SPSS

Berdasarkan tabel 3.5 dan tabel 3.6 menjelaskan bahwa hipotesis penelitian ini:

1. "Physical Evidence berpengaruh signifikan terhadap Customer Satisfaction pada pasien Klinik Kandungan dr.Iman, Sp.OG" dapat diterima sebab Tabel 5 menunjukkan bahwa Physical Evidence (X1) berpengaruh signifikan terhadap Customer Satisfaction (Y1), hal ini dibuktikan dengan nilai koefisien Beta 0,103 dan nilai signifikansi 0,015 ( $\mathrm{sig}<0,05)$.

2. "Trust berpengaruh signifikan terhadap pada pasien Klinik Kandungan dr.Iman, Sp.OG" dapat diterima sebab Tabel 5 Customer Satisfaction menunjukkan bahwa Trust (X2) berpengaruh signifikan terhadap Customer Satisfaction (Y1), hal ini 
IMKA Implementasi Manajemen \& Kewirausahaan - April, Vol. 1, No. 1, 30-42, 2021

dibuktikan dengan nilai koefisien Beta 0,443 dan nilai signifikansi 0,000 (sig < $0,05)$.

3. "E-Service Quality berpengaruh signifikan terhadap Customer Satisfaction pada pasien Klinik Kandungan dr.Iman, Sp.OG" dapat diterima sebab Tabel 5 menunjukkan bahwa E-Service Quality (X3) berpengaruh signifikan terhadap Customer Satisfaction (Y1), hal ini dibuktikan dengan nilai koefisien Beta 0,117 dan nilai signifikansi 0,043 ( $\mathrm{sig}<0,05$ ).

4. "Physical Evidence berpengaruh signifikan terhadap Customer Loyalty pada pasien Klinik Kandungan dr.Iman, Sp.OG” dapat diterima sebab Tabel 6 menunjukkan bahwa Physical Evidence (X1) berpengaruh signifikan terhadap Customer Loyalty (Y2), hal ini dibuktikan dengan nilai koefisien Beta 0,159 dan nilai signifikansi 0,004 (sig < 0,05).

5. "Trust berpengaruh signifikan terhadap Customer Loyalty pada pasien Klinik Kandungan dr.Iman, Sp.OG” tidak dapat diterima sebab Tabel 6 menunjukkan bahwa Trust (X2) tidak berpengaruh signifikan terhadap Customer Loyalty (Y2), hal ini dibuktikan dengan nilai koefisien Beta 0,110 dan nilai signifikansi 0,478 (sig $>0,05)$.

6. "E-Service Quality berpengaruh signifikan terhadap Customer Loyalty pada pasien Klinik Kandungan dr.Iman, Sp.OG" tidak dapat diterima sebab Tabel 6 menunjukkan bahwa E-Service Quality (X3) tidak berpengaruh signifikan terhadap Customer Loyalty (Y2), hal ini dibuktikan dengan nilai koefisien Beta 0,025 dan nilai signifikansi 0,731 (sig >0,05).

7. "Customer Satisfaction berpengaruh signifikan terhadap Customer Loyalty pada pasien Klinik Kandungan dr.Iman, Sp.OG" dapat diterima sebab Tabel 6 menunjukkan bahwa Customer Satisfaction (Y1) berpengaruh signifikan terhadap Customer Loyalty (Y2), hal ini dibuktikan dengan nilai koefisien Beta 0,931 dan nilai signifikansi $0,000(\mathrm{sig}<0,05)$.

\section{Uji F}

Tabel 7. Hasil Uji F

\begin{tabular}{|c|c|c|c|c|c|c|}
\hline \multicolumn{7}{|c|}{ ANOVA $^{\mathrm{a}}$} \\
\hline \multicolumn{2}{|c|}{ Model } & Sum of Squares & df & Mean Square & $\mathrm{F}$ & Sig. \\
\hline \multirow[t]{3}{*}{1} & Regression & 89.687 & 3 & 29.896 & 30.770 & $.000^{\mathrm{b}}$ \\
\hline & Residual & 93.273 & 96 & .972 & & \\
\hline & Total & 182.960 & 99 & & & \\
\hline
\end{tabular}

a. Dependent Variable: Customer Satisfaction

b. Predictors: (Constant), E-Service Quality, Physical Evidence, Trust

Sumber : Hasil Olah Data SPSS

Berdasarkan data tabel tersebut dapat diketahui bahwa nilai signifikan dari hasil perhitungan tabel ANOVA menunjukkan nilai 0,000 yang berarti lebih kecil dari nilai 
0,05 $(<0,05)$. Dengan melihat hasil tersebut dinyatakan bahwa hipotesis satu diterima, artinya Physical Evidence (X1), Trust (X2), dan E-Service Quality (X3) secara bersamasama mempengaruhi Customer Satisfaction (Y1).

Tabel 8. Hasil Uji F

\begin{tabular}{|c|c|c|c|c|c|c|}
\hline \multicolumn{7}{|c|}{ ANOVA $^{\mathbf{a}}$} \\
\hline \multicolumn{2}{|c|}{ Model } & Sum of Squares & df & Mean Square & $\mathrm{F}$ & Sig. \\
\hline \multirow[t]{3}{*}{1} & Regression & 291.449 & 4 & 72.862 & 46.813 & $.000^{\mathrm{b}}$ \\
\hline & Residual & 147.861 & 95 & 1.556 & & \\
\hline & Total & 439.310 & 99 & & & \\
\hline
\end{tabular}

a. Dependent Variable: Customer Loyalty

b. Predictors: (Constant), Customer Satisfaction, E-Service Quality, Physical Evidence, Trust Sumber : Hasil Olah Data SPSS

Berdasarkan data tabel tersebut dapat diketahui bahwa nilai signifikan dari hasil perhitungan tabel ANOVA menunjukkan nilai 0,000 yang berarti lebih kecil dari nilai 0,05 $(<0,05)$. Dengan melihat hasil tersebut dinyatakan bahwa hipotesis satu diterima, artinya Physical Evidence $\left(\mathrm{X}_{1}\right)$, Trust $\left(\mathrm{X}_{2}\right)$, E-Service Quality $\left(\mathrm{X}_{3}\right)$ dan Customer Satisfaction $\left(\mathrm{Y}_{1}\right)$ secara gabungan mempengaruhi Customer Loyalty $\left(\mathrm{Y}_{2}\right)$.

\section{Diagram Analisis Jalur}

Berdasarkan hubungan antar variabel, berikut adalah hasil model persamaan struktural dalam penelitian ini:

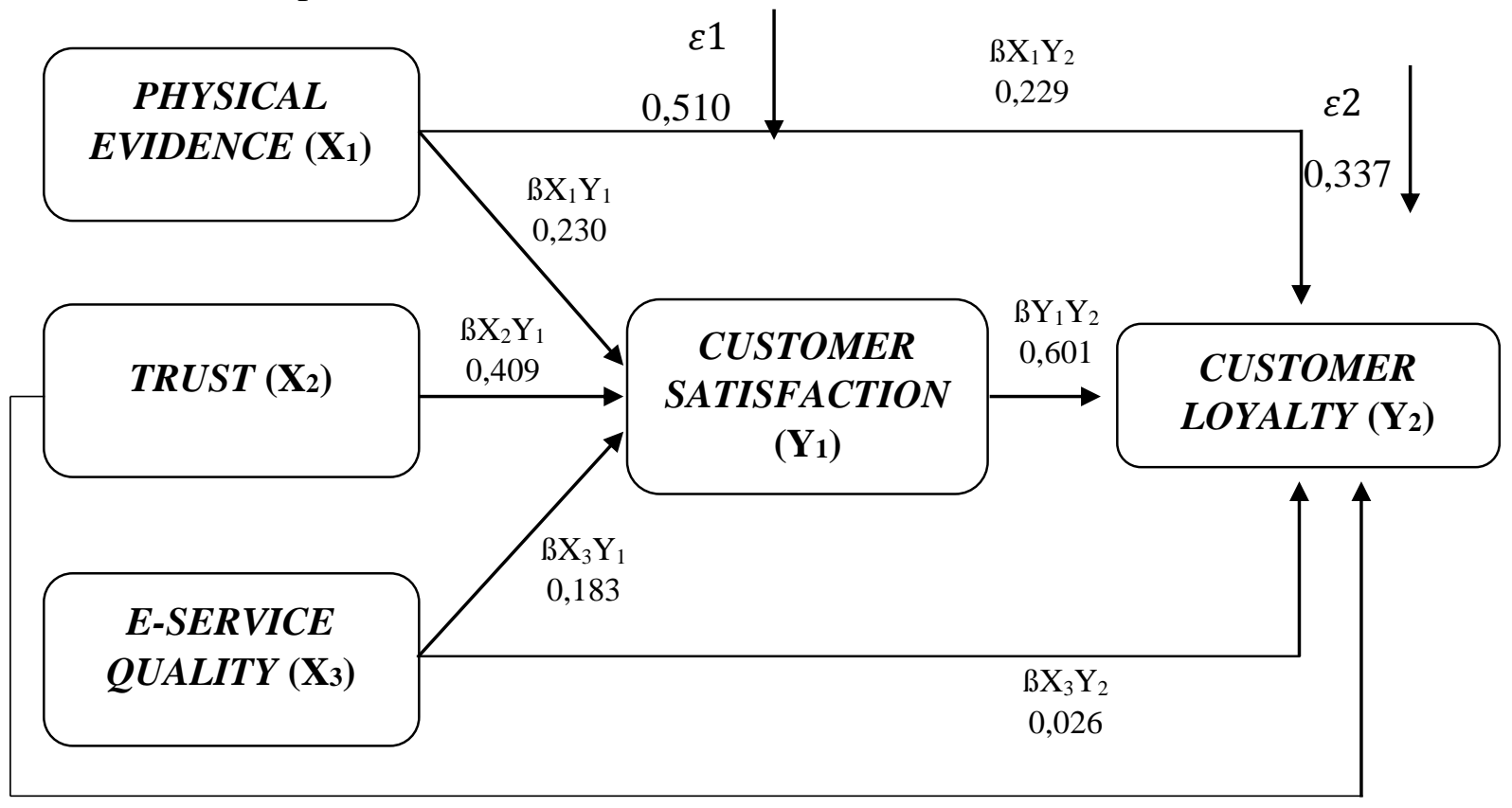

Gambar 1. Hasil Diagram Analisis Jalur 
Struktur 1

$\mathrm{Y} 1=0,230 \mathrm{X} 1+0,409 \mathrm{X} 2+0,183 \mathrm{X} 3+0,510 \varepsilon 1$

Struktur 2

$\mathrm{Y} 2=0,229 \mathrm{X} 1+0,065 \mathrm{X} 2+0,026 \mathrm{X} 3+0,601 \mathrm{Y} 1+0,337 \varepsilon 2$

\section{PEMBAHASAN}

\section{Pengaruh Physical Evidence Terhadap Customer Satisfaction}

Klinik Kandungan dr.Iman, Sp.OG memiliki sarana penunjang pemeriksaan juga sudah canggih, yakni menggunakan fasilitas USG 4D. Pemeriksaan menggunakan alat USG 4D ini belum tersedia di beberapa rumahsakit maupun praktek bidan mandiri di wilayah Surabaya Barat, khususnya di Kelurahan Kandangan, Benowo, Pakal, Sambikerep, dan daerah perbatasan Surabaya - Gresik. Alat USG 4D ini banyak diburu pasien karena hasil pemeriksaannya yang jauh lebih baik dibanding USG 2D, karena dengan USG 4D hasil gambar yang ditampilkan lebih terang dan suara yang dihasilkan lebih jelas. Klinik Kandungan dr.Iman, Sp.OG selain memperhatikan fasilitas pemeriksaan juga memperhatikan fasilitas lain untuk melengkapi kebutuhan pasien klinik, seperti adanya tempat sholat, kamar mandi, tempat bermain anak, apotik, ruang tunggu yang bersih dan nyaman, serta tempat parkir yang luas. Dengan beberapa hal yang diperhatikan tersebut membuat pasien klinik nyaman dan merasa puas ketika periksa di Klinik Kandungan dr.Iman, Sp.OG.

\section{Pengaruh Trust Terhadap Customer Satisfaction}

Dari hasil yang diperoleh dalam penelitian ini bahwa Trust (X2) berpengaruh signifikan terhadap Customer Satisfaction (Y1) maka dapat dikatakan bahwa semakin tinggi tingkat kepercayaan pasien terhadap klinik maka akan meningkatkan kepuasan pasien terhadap pemeriksaan di Klinik Kandungan dr.Iman, Sp.OG. Pasien yakin bahwa alat medis yang digunakan di Klinik Kandungan dr.Iman, Sp.OG dapat dipertanggungjawabkan, selain itu dokter yang menangani pemeriksaan juga memiliki kompetensi yang unggul, sehingga hasil pemeriksaan dapat tersampaikan dengan jelas dan dapat diterima pasien dengan baik.

\section{Pengaruh E-Service Quality Terhadap Customer Satisfaction}

Adanya pengaruh yang signifikan antara E-Service Quality (X3) terhadap Customer Satisfaction (Y1), hal tersebut membuktikan bahwa pihak Klinik Kandungan dr.Iman, Sp.OG berhasil memberikan pelayanan dengan memanfaatkan media elektronik. Kualitas layanan pemeriksaan di Klinik Kandungan dr.Iman, Sp.OG ditingkatkan dengan memanfaatkan perkembangan teknologi, yakni dengan 
memberikan layanan elektronik (E-Service Quality). Salah satu kualitas layanan elektronik tersebut adalah klinik ini sudah menggunakan sistem online untuk antriannya. Sistem antrian secara online dapat memudahkan para pasien untuk mendaftar, khususnya bagi pasien yang bertempat tinggal jauh dari lokasi klinik, sehingga dapat lebih menghemat biaya transportasi. Selain itu, pasien juga dapat memperkirakan kedatangan periksa ke klinik berdasarkan nomor antrian yang diperoleh.

\section{Pengaruh Physical Evidence Terhadap Customer Loyalty}

Dengan kualitas alat pemeriksaan yang sudah canggih, kondisi klinik yang menarik, keunggulan alat medis dan dokter, serta fasilitas pelengkap klinik lain yang ada pada Klinik Kandungan dr.Iman,Sp.OG, dapat meningkatkan kepuasan pasien, sehingga membuat pasien loyal pada Klinik Kandungan dr.Iman, Sp.OG, dan tak sedikit pula yang merekomendasikan kepada orang lain.

\section{Pengaruh Trust Terhadap Customer Loyalty}

Tidak adanya pengaruh Trust (X2) terhadap Customer Loyalty (Y2) ini disebabkan karena seringnya kepercayaan pasien terhadap klinik yang tidak sengaja terabaikan, misalnya seperti ketidaktepatan waktu pemeriksaan dengan nomor urut yang diperoleh saat pendaftaran, hal ini sering terjadi karena jadwal praktek dokter di klinik terbentur dengan jadwal penanganan pasien di Rumah Sakit, mengingat dr.Iman merupakan dokter spesialis kandungan yang praktek di beberapa Rumah Sakit di Surabaya Barat. Selain itu terkadang nomor urut pemeriksaan tidak berdasarkan nomor urut yang diperoleh, melainkan dari kedaruratan keadaan pasien.

\section{Pengaruh E-Service Quality Terhadap Customer Loyalty}

Tidak adanya pengaruh E-Service Quality (X3) terhadap Customer Loyalty (Y2) ini disebabkan karena sulitnya melakukan pendaftaran secara online dikarenakan ramainya pasien yang mendaftar, selain itu kendala sinyal juga mempengaruhi loading dari internet itu sendiri, sehingga terdahului oleh pasien-pasien yang mendaftar ontime dengan tingkat sinyal yang tinggi.

\section{Pengaruh Customer Satisfaction Terhadap Customer Loyalty.}

Memenangkan hati pasien dengan membuat mereka merasa puas adalah tujuan utama Klinik Kandungan dr.Iman, Sp.OG, karena dengan meningkatkan kepuasan pasien maka akan berdampak pada loyalitas pasien terhadap Klinik Kandungan dr.Iman, Sp.OG. Loyalitas konsumen didorong dengan adanya kepuasan yang dirasakan oleh konsumen akan bukti fisik yang ada, dimana respon dari konsumen dari perilaku yang ditunjukan oleh konsumen dengan membandingkan antara kinerja atau hasil yang dirasakan dengan harapan yang diterima konsumen akan bukti yang terlihat saat 
melakukan atau merasakan setelah kunjungan pada tempat tersebut. Ketika konsumen puas, konsumen akan berperilaku positif. Perilaku positif konsumen dapat berupa pembelian ulang produk atau layanan yang pernah dirasakan, hal ini berarti semakin tinggi tingkat kepuasan konsumen akan meningkatkan loyalitas konsumen. Klinik Kandungan dr.Iman,Sp.OG berusaha semampu mungkin untuk dapat selalu memenuhi kebutuhan pasien, seperti dengan mengupdate kualitas alat medis, menambah kelengkapan dari kebutuhan pemeriksaan, mengupdate skill dari seluruh pihak yang terlibat dalam manajemen klinik, serta membuat klinik tampak bersih, nyaman, menarik.

\section{KESIMPULAN}

Berdasarkan dari deskripsi hasil penelitian dan pembahasan yang telah diuraikan pada bab sebelumnya, maka dapat diambil kesimpulan bahwa Physical Evidence berpengaruh positif dan signifikan terhadap Customer Satisfaction. Trust berpengaruh positif dan signifikan terhadap Customer Satisfaction. E-Service Quality berpengaruh positif dan signifikan terhadap Customer Satisfaction. Physical Evidence berpengaruh positif dan signifikan terhadap Customer Loyalty. Trust berpengaruh positif dan tidak signifikan terhadap Customer Loyalty. E-Service Quality berpengaruh positif dan tidak signifikan terhadap Customer Loyalty. Customer Satisfaction berpengaruh positif dan signifikan terhadap Customer Loyalty.

Pada Klinik Kandungan dr.Iman,Sp.OG variabel Physical Evidence (X1) memiliki pengaruh yang sangat baik terhadap Customer Satisfaction (Y1) dan Customer Satisfaction (Y2). Hal ini dikarenakan banyak pasien yang memeriksakan diri ke dr.Iman melihat dari segi kecanggihan alat pemeriksaan kehamilan yakni menggunakan alat USG 4D. Pada variabel Trust (X2) dan E-Service Quality (X3) terhadap Customer Satisfaction (Y1) juga memiliki pengaruh yang cukup baik karena harapan pasien telah terpenuhi dengan variabel tersebut. Namun pada variabel Trust (X2) dan E-Service Quality (X3) terhadap Customer Loyalty (Y2), secara langsung tidak memiliki pengaruh yang signifikan. Hal ini disebabkan untuk mencapai keloyalitasan dari pelanggan tidaklah mudah. Sehingga dapat disimpulkan Customer Satisfaction (Y1) tepat menjadi variabel intervening untuk mencapai Customer Loyalty (Y2), karena loyalitas dapat tercapai ketika pelanggan merasa puas terlebih dahulu.

Dari hasil penelitian variabel Trust (X2) dan E-Service Quality (X3) tidak berpengaruh signifikan terhadap tingkat Customer Loyalty (Y2), maka manajemen Klinik Kandungan dr.Iman, Sp.OG harus lebih memperhatikan lagi variabel-variabel tersebut. Hal tersebut apabila tidak ditingkatkan lagi tentunya akan merugikan Klinik Kandungan dr.Iman,Sp.OG yaitu akan kehilangan pasien dan beralih ke tempat pemeriksaan yang lain. Hal ini bisa diantisipasi dengan sedikit mengurangi jadwal penanganan di Rumah Sakit ketika dr.Iman,Sp.OG sedang membuka praktek di klinik. Selain itu jadwal pemeriksaan di klinik bisa ditambah jam buka, sehingga kuota pasien yang dapat ditangani juga bisa lebih banyak. Untuk memperbaiki variabel E-Service 
Quality, bisa diantisipasi dengan memberi info, pada sistem informasi atau website yang digunakan untuk pendaftaran, ketika dr.Iman,Sp.OG sedang tidak praktek di klinik, baik karena agenda libur (pasti dan incidental) ataupun ada jadwal penanganan pasien di Rumah Sakit, sehingga pasien yang sudah mendaftar maupun yang belum mendaftar dapat mengetahui dr.Iman, Sp.OG sedang praktek di klinik atau tidak. Hal ini diharapkan dapat memperbaiki kualitas E-Service Quality yang berdampak pada Trust sehingga berpengaruh signifikan terhadap Customer Loyalty. Memberikan layanan terbaik, mengutamakan keramah tamahan terhadap pasien, dan menjelaskan secara transparan apapun hasil pemeriksaan kepada pasien. Selain itu manajemen klinik juga harus terus mengupdate standar kualitas dari alat-alat medis, dan kelengkapan dari alatalat medis yang dibutuhkan. dr.Iman, Sp.OG juga harus terus meng-update ilmu sehingga pengalaman yang dimiliki jauh lebih kompeten. Obat yang disediakan di klinik harus bisa lebih bervariasi dan tersedia dengan lengkap, sehingga kebutuhan pasien dapat secara langsung terpenuhi tanpa perlu mencari apotek lain diluar klinik. Bagi pasien yang memiliki nilai religi cukup tinggi bisa di antisipasi dengan menambah perawat perempuan yang memiliki kemampuan ilmu untuk membantu dokter saat menangani kebutuhan medis, khususnya penanganan medis intim.

\section{DAFTAR PUSTAKA}

Arief, S., dan Elvira, A. (2017). Pengaruh Kualitas Pelayanan Terhadap Loyalitas Pelanggan (Studi Kasus Pada Apotek Telkomedika Sentot, Buah Batu, Dan Gerlong). e-Proceeding of Management, .4(3), 2382-2392

Assauri, Sofjan. (2010). Manajemen Pemasaran: Dasar, Konsep \& Strategi. Jakarta: Grafindo.

Ganang, S., dan Sri, W. (2017). Pengaruh Bukti Fisik dan Empati Terhadap Loyalitas Konsumen Melalui Kepuasan Konsumen (Studi Pada Minimo Ice Cream Resto Semarang). Management Analysis Journal, 3(2), 225-252.

Jeremia, K., dan Djurwati, P. (2019). Pengaruh Service Quality, Trust, Dan Consumer Satisfaction Terhadap Consumer Loyalty Pada Cv. Sarana Marine Fiberglass. Jurnal Emba: Jurnal Riset Ekonomi, Manajemen, Bisnis Dan Akuntansi, 7(1), 831-840.

Kotler, P,. dan Keller. (2012). Marketing Management $14^{\text {th }}$ edition. Jakarta: PT. Indeks Kelompok Gramedia.

Laely, N. (2016). Analisis Pengaruh Kepercayaan dan Harga Terhadap Loyalitas Pelanggan Dimediasi Kepuasan Pada PT. Telkomsel di Kota Kediri. Jurnal Ilmu Ekonomi \& Manajemen, 3(2), 61-74.

Laurent, F. (2016). Pengaruh E-Service Quality Terhadap Loyalitas Pelanggan Go-Jek Melalui Kepuasan Pelanggan. Journal of Business Studies, 2(1), 2443-3837.

Lupiyoadi, R. (2013). Manajemen Pemasaran Jasa. Jakarta: Salemba Empat.

Mega, D., Imam, S., dan Zainul, A. (2017). Pengaruh E-Service Quality Dan E-Trust Terhadap E-Customer Satisfaction Serta Implikasinya Terhadap E-Customer Loyalty (Studi pada Nasabah PT Bank Rakyat Indonesia (Persero) Tbk, Kantor Cabang Pembantu Lawang). Jurnal Administrasi Bisnis, 38(2), 67-79. 
IMKA Implementasi Manajemen \& Kewirausahaan - April, Vol. 1, No. 1, 30-42, 2021

Ratlan, P,. dan Renhard, M. (2014). Analisis Jalur Teori Dan Aplikasi Dalam Riset Bisnis. Jakarta: Rineka Cipta.

Sugiyono. (2017). Metode Penelitian Kuantitatif, Kualitatif, dan R\&D. Bandung: Alfabeta.

Sutarno. (2012). Serba-Serbi Manajemen Bisnis. Yogyakarta: Graha Ilmu. Tjiptono, F. (2012). Pemasaran Strategik. Yogyakarta: Penerbit Andi. 